\title{
Experimental Comparison of HFT Pair Trading Strategies Using the Data of Microsecond and Nanosecond Future Commodity Contracts
}

\author{
Mantas VAITONIS, Saulius MASTEIKA \\ Vilnius University, Kaunas Faculty, Muitines 8, LT-44280 Kaunas, Lithuania \\ mantas.vaitonis@knf.vu.lt, saulius.masteika@knf.vu.lt
}

\begin{abstract}
Nowadays, it is not necessary for humans to conduct trade; this task is performed by trading algorithms. The speed of trading is of the most importance, however, there are relatively few aoutademic researches on the increased speed of trading from milliseconds to nanoseconds. In order to address the aforementioned shortcoming, this research measures the differences in the effectiveness of the pairs trading strategies, emerging when microsecond and nanosecond data are included. The effect of the increased speed of data is analysed. We present different pairs trading strategies and one pair selection algorithm, based on the cointegration method. These trading strategies are implemented on five different commodity futures contracts using both microsecond and nanosecond historical data. The effectiveness is measured in accordance with the profit, generated at the end of the trading period. In order to measure the effectiveness of all presented pairs trading strategies, the Sharpe Ratio method was introduced.
\end{abstract}

Keywords - high frequency trading, statistical arbitrage, pairs trading, algorithmic trading, pair selection, correlation.

\section{Introduction}

All financial markets use a simple trading rule: buy when the price is low and sell when it is high. Many strategies are developed on the basis of the aforementioned principle. One type of such strategies is pure arbitrage - a zero-risk type of strategy. An example of this type of trading is buying and selling a financial instrument with a different value in two or more different markets. In turn, the profit comes from the difference in prices.

There exists another type of arbitrage called statistical arbitrage which is not riskfree. Importantly, these trading strategies are aimed at the expected gain which is greater than the risk and the profit that comes from mispricing the financial instruments.

The mispricing of the financial instrument comes from any financial instrument according to its expected futures trading value with regard to its spot price. Statistical arbitrage trading strategies evolved from other type of trading, i.e., pairs trading, which 
exploits the mean reversion in the performance of identified pair of financial instruments based on the different criteria (Ahmet, 2015; Madhavaram, 2013).

It should be noted that pairs trading strategy consists of two dimensions with a pair of financial instruments that have followed each other over the given period of time. As it has already been mentioned, pairs trading is defined by statistical arbitrage strategy that searches for temporary mispricing of two financial instruments which are expected to come back to their mean due to the strong historical co-movement. In order to make profit using statistical arbitrage, a trader has to take a long position on the financial instrument with relatively low price and take a short position on the overpriced one. When these positions are taken for a pair of two financial instruments that follow each other, the strategy is considered as risk-free. As for the price converge, the opposite positions are taken. Thus, it might be stated that the profitability of statistical arbitrage strategy depends on the following two factors: the first one is to identify a pair of financial instruments that are highly correlated and the second factor is the modelling of dependency structure between the two financial instruments to measure the degree of relative mispricing (Vidyamurthy, 2004; Krauss, 2015; Driaunys et al., 2014; Lau et al., 2016).

It is well known that developments in computer technology have changed the way financial instruments are traded. Nowadays, a significant part of trades is handled without human intervention, where trading algorithms make trading decisions. Although the concept of algorithmic trading is not brand new, the speed in which algorithmic trading operates has grown tremendously over the past ten years.

The trade execution time has grown from daily trading to microseconds and even nanoseconds. Due to the increase in speed, a huge number of orders and order cancellations are required. Profit chances for high frequency traders are very timesensitive and low latency for trade execution is of the main importance. Thus, HFT firms invest in high-speed connections and place their trading platforms close to the stock market servers via co-location (Kaya, 2016).

The main aim of this research is to test multidimensional pairs trading, using statistical arbitrage that trades five futures contracts as a group with different pairs trading strategies with microsecond and nanosecond data, and to compare their results based on the frequency of the data used. The first strategy employed in this research was presented by M. S. Perlni. In his paper, he used the strategy on daily data of Brazilian market (Perlini, 2009). The second strategy was researched by D. Herlemont. On his paper about pairs trading (Herlemont, 2013). The last strategy was presented by J. Cladeira and G. V. Moura in their research about statistical arbitrage (Caldeira and Moura, 2013). The main objective of the research is not to test pair trading strategies, but to compare the effectiveness of the different frequency data, when they are presented to same environment. All specified pairs trading strategies have not been used with high frequency data and have not been adapted to high frequency trading until present research. Thus, they had to be modified to meet the needs of this research. Importantly, not only pairs trading strategies, but also the method of pairs selection is introduced in this research. The aforementioned method has not been used with nanosecond historic data records.

It should be noted that there are different methods for two-dimensional pairs trading. One of the most popular is distance method, which has been analysed in the previous research (Driaunys et al., 2014; Masteika and Vaitonis, 2015; Vaitonis and Masteika, 2016). The popularity of this method may be attributed to the use of simple linear correlation coefficient as a measure of dependence which makes the 
implementation convenient (Lau, 2016). There are other researches that extend the study of the distance method. However, none of these studies are based on high frequency trading. Therefore, we introduced some research on this theme.

Next method for pairs selection is cointegration. The pairs selection algorithm is based on this method, using Augmented Dickey Fuller Test, Engle and Grangers 2-step approach and Johansen test (Caldeira and Moura, 2013).

The rest of the paper is organised as follows: background theory and the problem statement are presented in Sections 2 and 3, the methodology, including the pairs trading strategy and pairs selection algorithm, is presented in Sections 4 and 5. Section 6 introduces the pairs trading testing framework and experimental settings, the results and the summary of the research, followed by conclusions in Section 7.

\section{Statistical arbitrage}

Correlation is a statistical technique that show how two variables are related to each other. In other words this term defines the strength of a relationship between two variables. The main idea of statistical arbitrage or pairs trading is to find the pair of financial instruments that are highly correlated. When a pair is found, a trader must look for the changes in correlation followed by mean-reversion to the trend of financial instruments pair, thereby, creating a profit opportunity. This type of trading needs to identify a relationship between two financial instruments, figure out the direction of their relationship, and execute long and short positions, based on the statistical data presented. Selecting a good pair for trading becomes the most important stage of mean-reversion of the market-neutral statistical arbitrage strategy (Miao and Clements, 2002; Zubulake and Lee, 2011; Aldridge, 2013).

\subsection{Pairs trading using correlation}

The relationship between two financial instruments, which is based on the tendency that both of them tend to move together is called correlation. When the pair of financial instruments is highly correlated, one must look for abnormal behavior among this pair, find out why the prices might be separated and attempt to make profit through convergence. In order to find a pair for the selected financial instrument, we must calculate the correlation coefficient or use minimum distance criteria like minimal squared distance between two normalized prices. The best fit is selected by choosing the one with the smallest minimal squared distance (Lau et al., 2016; Miao and Clements, 2002).

\subsection{Pairs trading using cointegration}

The cointegration method uses mathematical model, developed by Engle and Granger (Engle and Granger, 1987), which has attracted a considerable interest of economists over the last two decades. Cointegration states that, in some instances, despite two given non-stationary time series, a specific linear combination of the two time series is actually stationary. The two time series move together in a lockstep 
fashion. The cointegration can be described like two time series $x_{t}$ and $y_{t}$ that are nonstationary. If there was a parameter $\gamma$ and the following equation:

$$
z_{t}=y_{t}-\gamma x_{t}
$$

was a stationary process, then $x_{t}$ and $y_{t}$ would be cointegrated. This path-breaking process emerged as a powerful tool for investigating common asset trends in multivariate time series (Miao, 2014).

\section{High frequency trading}

Nowadays, financial markets are fully automated, consisting of algorithmic trading, thus, they are largely dominated by high frequency trading (Fox et al., 2015). HFT refers to the increasingly widespread practice of using algorithmic programmes to execute trades, based on split-second changes in market conditions. High frequency trading platforms have replaced the traditional auction-like floor where traders compete on price (Fox et al., 2015). The main focus of HFT is to beat the time. Most of the high frequency traders consist of the so-called market makers. Market makers are in high demand for markets with low liquidity, where they operate on the basis of algorithms that balance supply and demand. Thus, market makers most of the time pay low or even no commissions in these markets (Herlemont, 2013; Zubulake and Lee, 2011; Brogaard et al., 2013; Jaramillo, 2016). The economics and finance academic community consider HFT as beneficial to the market because HFT provides liquidity and, therefore, facilitates the flow of commerce in the capital markets (Jaramillo, 2016).

It should be emphasized that high frequency trading is a term used to describe ultra-fast electronic trading in which participants hold positions for short periods (Ahmed et al., 2009). Given the fact that high frequency trading has to be done in milliseconds or even nanoseconds, all trading must be performed by using supercomputer, which gives the possibility to execute trades in the fastest manner. In real life, depending on the trade, trading opportunities can last from nanoseconds to minutes or even hours.

In brief, high frequency algorithmic trading is a form of automated trading that is characterized by:

a) Computer algorithms for decision making, trading rules, etc., that help to trade in electronic markets without or with minimal human interaction;

b) Technology for low-latency that helps to speed up and minimize the response time of each transactions, which includes co-location servers;

c) High speed connections to electronic markets;

d) High message rates (orders, quotes or cancellations).

In fact, high frequency trading has grown rapidly over the last two decades. By 2010 , the share of high frequency trading in total equity boomed from almost zero (in 2005) to $40 \%$ in Europe. For example, by 2005 high frequency trading accounted for approximately $20 \%$ of the trades in the US and peaked to $60 \%$ in 2009 . Then, financial crises took place, and by 2014 the share of high frequency equity markets fell down to $35 \%$ and $50 \%$ of the total market in Europe and the US, respectively (Kaya, 2016).

It is evident that at the moment HFT accounts for approximately $55 \%$ of the trading volume in the US equity markets and about $40 \%$ in European equity markets (Krauss, 2015). While speaking of the futures markets, which this research is based on, HFT 
share has grown as well. CFTC found that during the period from October 2012 to October 2014, the algorithmic trading systems were present on at least one side in nearly $80 \%$ of the foreign exchange futures trading volume; $67 \%$ of the interest rate futures volume; $62 \%$ of the equity futures volume; $47 \%$ the of metals and energy futures volume; and $38 \%$ of the agricultural product futures volume. Algorithmic trading has also grown up to $67 \%$ of the trading in 10-year Treasury Futures and $64 \%$ of the Eurodollar Futures Markets (Miller and Shorter, 2016).

Trading strategies, used by high frequency traders, seek for the opportunity to exploit short-lived trading in the markets that would not be possible to find or identify in other way than high-speed processing power of computers. These trading opportunities are very small abnormalities in the pricing of financial instruments that result in extra low profit per trade. High frequency earns higher profit as it is possible to trade in big volumes. Thus, profit can be generated from these small changes in the prices.

\subsection{Selection of futures contracts and data sample}

During our research, nanosecond and microsecond data was selected. As it has already been mentioned, this type of data was used due to the fact that our research is based on testing of different frequency of data and finding out the effect it has on the trading strategies. It was interesting to find out whether higher frequency data provide the strategy with the advantage when presented to the same environment and same parameters.

\subsection{Data}

The nanosecond and microsecond data were provided by Nanotick company. Futures contract data are from ME group which consists of NYMEX, COMEX and CBOT. Nanotick provided five different futures commodity contracts: NG (natural gas), BZ (Brent crude oil), CL (crude oil), HO (NY Harbor ULSD), RB (RBOB Gasoline). Time period of commodity futures contracts was from 01-08-2015 to 31-08-2015.

After normalization, microsecond futures commodity contracts data consisted of 24957994 records and nanosecond - 287872500 records per contract. Thus, the total amount of lines processed during this research was 1564152470.

Upon preparation, three different statistical arbitrage trading strategies had to be applied to the data. The authors used their strategies on low frequency data (daily, hourly), while the previous research adapted the strategies to work with high frequency data. Every strategy performance was measured by profit it generated at the end of entire trading period.

\section{Methodology}

The main purpose of pairs trading is to find two financial instruments that move together. Once the pair of these instruments is found, the strategy has to decide when to take long and short positions based on the trading rules. Following the research, six main steps of pairs trading strategy were identified:

1. Selection of the size of the window trading and data normalization;

2. Data normalization; 
3. Selection of the correlated pair;

4. Definition of the trading rules;

5. Trading;

6. Assessment of the pairs trading strategy (Driaunys et al., 2014; Masteika and Vaitonis, 2015; Vaitonis and Masteika, 2016).

Before selecting the trading and data normalization window, every strategy must be trained. Thus, before starting to trade, some data must be used for training the strategy. This data may be called out of sample data. All data of microsecond and nanosecond futures commodity contracts had to be divided into training and testing datasets. The method of dividing data into training and testing periods was referred to as the holdout method in statistical classification (Miao and Clements, 2002). When selecting training or out of sample period, it is important to select the right size of this window: if the chosen window is too big, the strategy may overtrain and if it is too small the strategy will not be able to notice the abnormal behaviour (Perlin, 2009). Finally, the testing period follows immediately after the training period.

\subsection{Data normalization}

Upon receiving the nanosecond and microsecond data for our commodity futures contracts, next step was to normalize these data to be able to implement them in our test environment. The first task was to bring time stamp data together. For example, if we have a time stamp of 17:00:00.869053009 in one contract and the time stamp of 17:00:00.825207610 in other futures contract, these two time stamps have to appear in both contracts. In our case, all different time stamps had to appear in all five different futures contacts. Data samples are presented in Table 1 and Table 2.

Table 1. The example of nanosecond historical data

\begin{tabular}{|rlllll}
\hline Receiving Date & Receiving Time & Symbol & Asset & $\begin{array}{l}\text { Entry } \\
\text { Type }\end{array}$ & $\begin{array}{l}\text { Entry } \\
\text { Price }\end{array}$ \\
\hline 20150809 & $17: 00: 00.869053009$ & NGF6 & NG & A & 3227 \\
\hline 20150809 & $17: 00: 00.869053009$ & NGF6 & NG & B & 3221 \\
\hline 20150809 & $17: 00: 00.930168164$ & NGF6 & NG & A & 3226 \\
\hline 20150809 & $17: 00: 00.930168164$ & NGF6 & NG & B & 3221 \\
\hline 20150809 & $17: 00: 01.017456320$ & NGF6 & NG & A & 3226 \\
\hline 20150809 & $17: 00: 01.017456320$ & NGF6 & NG & B & 3219 \\
\hline 20150809 & $17: 00: 01.059840559$ & NGF6 & NG & A & 3227 \\
\hline 20150809 & $17: 00: 01.059840559$ & NGF6 & NG & B & 3219 \\
\hline 20150809 & $17: 00: 01.156791713$ & NGF6 & NG & A & 3238 \\
\hline 20150809 & $17: 00: 01.156791713$ & NGF6 & NG & B & 3216 \\
\hline 20150809 & $17: 00: 01.204683812$ & NGF6 & NG & A & 3238 \\
\hline 20150809 & $17: 00: 01.204683812$ & NGF6 & NG & B & 3216 \\
\hline 20150809 & $17: 00: 01.205605232$ & NGF6 & NG & A & 3238
\end{tabular}




\begin{tabular}{|lllllll}
\hline 20150809 & $17: 00: 01.205605232$ & NGF6 & NG & B & 3215 \\
\hline 20150809 & $17: 00: 01.206755867$ & NGF6 & NG & A & 3238 \\
\hline 20150809 & $17: 00: 01.206755867$ & NGF6 & NG & B & 3215 \\
\hline 20150809 & $17: 00: 01.207350519$ & NGF6 & NG & A & 3231 \\
\hline 20150809 & $17: 00: 01.207350519$ & NGF6 & NG & B & 3215 \\
\hline 20150809 & $17: 00: 01.208805474$ & NGF6 & NG & A & 3231 \\
\hline 20150809 & $17: 00: 01.208805474$ & NGF6 & NG & B & 3217 \\
\hline 20150809 & $17: 00: 01.224604710$ & NGF6 & NG & A & 3233 \\
\hline 20150809 & $17: 00: 01.224604710$ & NGF6 & NG & B & 3217 \\
\hline
\end{tabular}

Table 2. The example of nanosecond historical data

\begin{tabular}{|r|lllll|}
\hline Receiving Date & Receiving Time & Symbol & Asset & $\begin{array}{l}\text { Entry } \\
\text { Type }\end{array}$ & $\begin{array}{l}\text { Entry } \\
\text { Price }\end{array}$ \\
\hline 20150809 & $17: 00: 00.825207610$ & HOF6 & HO & A & 16040 \\
\hline 20150809 & $17: 00: 00.825207610$ & HOF6 & HO & B & 15950 \\
\hline 20150809 & $17: 00: 00.826021615$ & HOF6 & HO & A & 16035 \\
\hline 20150809 & $17: 00: 00.826021615$ & HOF6 & HO & B & 15950 \\
\hline 20150809 & $17: 00: 00.838609766$ & HOF6 & HO & A & 16040 \\
\hline 20150809 & $17: 00: 00.838609766$ & HOF6 & HO & B & 15950 \\
\hline 20150809 & $17: 00: 00.865890817$ & HOF6 & HO & A & 16040 \\
\hline 20150809 & $17: 00: 00.865890817$ & HOF6 & HO & B & 15945 \\
\hline 20150809 & $17: 00: 00.866430043$ & HOF6 & HO & A & 16040 \\
\hline 20150809 & $17: 00: 00.866430043$ & HOF6 & HO & B & 15944 \\
\hline 20150809 & $17: 00: 00.867756129$ & HOF6 & HO & A & 16040 \\
\hline 20150809 & $17: 00: 00.867756129$ & HOF6 & HO & B & 15943 \\
\hline 20150809 & $17: 00: 00.869125205$ & HOF6 & HO & A & 16040 \\
\hline 20150809 & $17: 00: 00.869125205$ & HOF6 & HO & B & 15938 \\
\hline 20150809 & $17: 00: 00.875541527$ & HOF6 & HO & A & 16040 \\
\hline 20150809 & $17: 00: 00.875541527$ & HOF6 & HO & B & 15934 \\
\hline 20150809 & $17: 00: 00.884336757$ & HOF6 & HO & A & 16040 \\
\hline 20150809 & $17: 00: 00.884336757$ & HOF6 & HO & B & 15928 \\
\hline 20150809 & $17: 00: 01.025686712$ & HOF6 & HO & A & 16040 \\
\hline 20150809 & $17: 00: 01.025686712$ & HOF6 & HO & B & 15950 \\
\hline 20150809 & $17: 00: 01.029573686$ & HOF6 & HO & A & 16019 \\
\hline 20150809 & $17: 00: 01.029573686$ & HOF6 & HO & B & 15950 \\
\hline & & & & & \\
\hline
\end{tabular}


If the contract is filled with a new time stamp, the price for that futures contract is set the same as the last time stamp. It is assumed that the price did not change for that time. In this way, all time stamps of futures contracts are normalized for nanosecond and microsecond data (Masteika and Vaitonis, 2015; Vaitonis and Masteika, 2016).

As all time stamps for all the futures contracts were obtained, it was time to define data for training which is out of sample, normalization and trading periods. The out of sample period is used only for training strategies and is not later used for trading. During this procedure, all parameters were kept the same: out of sample period (training period) was 5 minutes, normalization and trading period was kept the same, i.e., 20 seconds for each trading window. It was kept the same when using nanoseconds and microseconds in order to measure the effectiveness of the data. Another period of 20 seconds was selected for closing the positions. It should be noted that a closing period is necessary, if there are no signals to close the positions and not to keep the position opened for too long. The selected parameters were based on our previous researches were we tested high frequency trading using microsecond data (Masteika and Vaitonis, 2015; Vaitonis and Masteika, 2016; Vaitonis and Masteika, 2017). Moreover it was necessary to test if the same parameters would work with nanosecond data. During this part the different sizes of window was used to find the one which did result in better performance with trading strategies presented in this research. The size of window used was form 10 to 60 seconds with the step of 10 seconds. In the figure below three days of our research are presented in more detail (2015-08-03, 2015-08-14 and 2015-08-31).

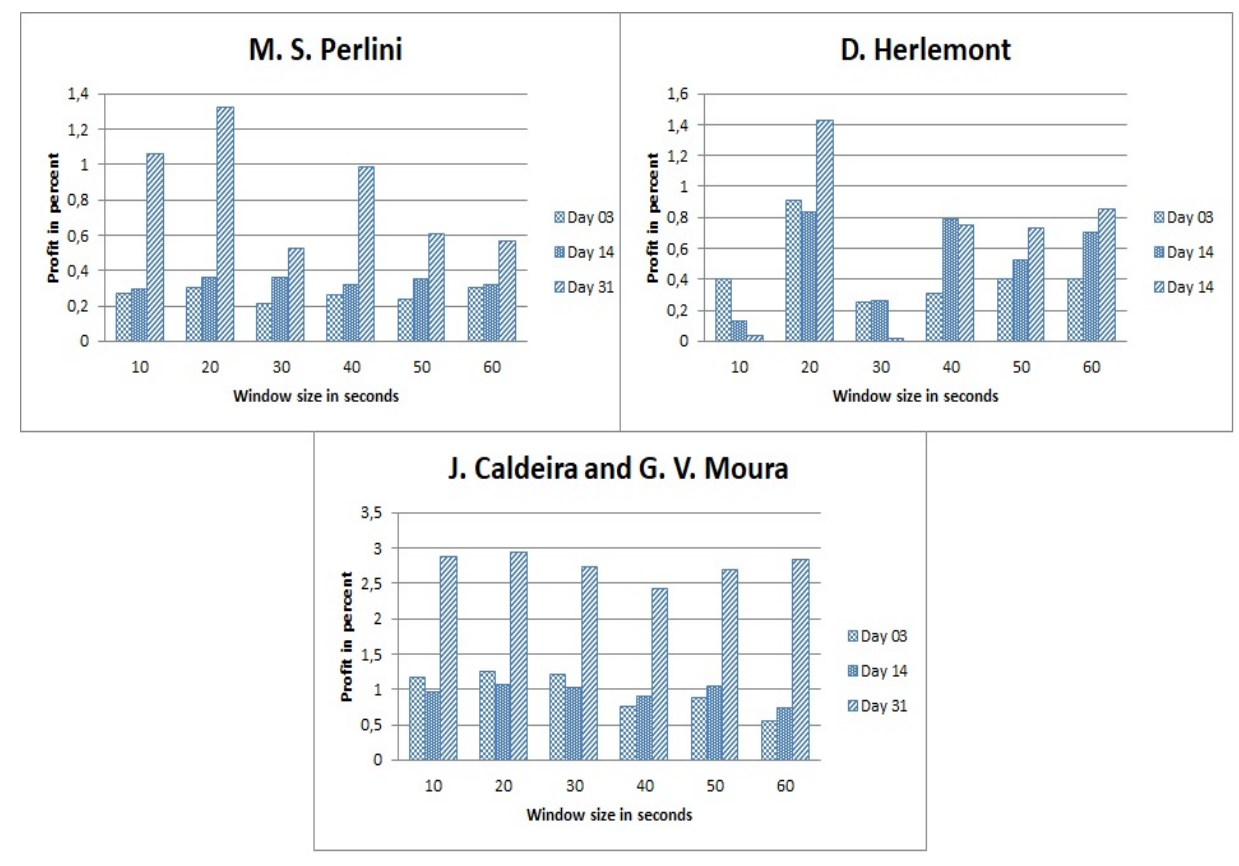

Fig. 1. Pair trading strategies comparison using different trading and data normalization window 
All of the above charts illustrate the profitability of each trading strategy during each of the aforementioned days using different window for trading and data normalization. The result proved to be the same as with microsecond data, that best performance is achieved with window the size of 20 second and it was used during all of this research.

The more detailed research in parameters changing will be presented in future works, where high frequency data will applied to GPU. Upon setting and defining the above parameters on the trading strategies, price normalization follows. The normalization of prices is required due to the fact that every futures commodity has different pricing, therefore, it would be difficult to compare the prices, to look for trading signals and to find correlation. Nanosecond and microsecond normalization is done in the same way: for each price of futures commodity contract $P(i, t)$, we calculate empirical mean $\mu(i, t)$ and standard deviation $\sigma(i, t)$ for the selected normalization period, and then apply the following equation (Perlin, 2009):

$$
p(i, t)=\frac{P(i, t)-\mu(i, t)}{\sigma(i, t)} .
$$

Value $p(i, t)$ is the normalized price of futures commodity contract $i$ at time $t$ (Perlin, 2009). The method used for normalization is $\mathrm{z}$-score. There are other methods for normalization, for instance, min-max, decimal scaling, sliding window, etc., however, the experiment is based on measuring the importance of data, thus, the normalization method, which has been more widely used on statistical arbitrage, i.e., zscore, was selected (Bogoev and Karam, 2016).

\subsection{Pair selection (correlation)}

One of two main parts of this trading methodology is the pairs selection algorithm which is essentially based on cointegration testing. In our previous research, minimum squared distance method was used for selecting the trading pairs (Driaunys et al., 2014; Masteika and Vaitonis, 2015; Vaitonis and Masteika, 2016). Minimum squared distance method is a distance method. However, for this research the cointegration method was selected to detect the trading pairs.

Cointegration method involves the following steps:

1. Identification of futures contract pairs that could potentially be cointegrated;

2. Once the potential pairs are identified, verification of the proposed hypothesis that the futures contract pairs are indeed cointegrated based on the information from historical data;

3. Examine the cointegrated pairs to determine whether they can be trade on (Vidyamurthy, 2004).

The objective of this phase is to identify the pairs with linear combination exhibiting a significant predictable component that is uncorrelated with underlying movements in the market as a whole. Having this aim, we first measure the spread of pair prices for stationarity. In this research, it is done by checking whether the data series are integrated in the same order by using Augmented Dickey Fuller Test (ADF), which is the extended version Dickey Fuller (Caldeira and Moura, 2013). Dickey Fuller tests were used for stationarity, which examine the null hypothesis of an autoregressive integrated moving average against stationary and alternatively. In this step, we test the null hypothesis of whether a process has a unit root (is not stationary). If the pair is 
cointegrated, the spread should be stationary (Bogoev and Karam, 2016; Mushtaq, 2011). Augmented Dickey Fuller Test (ADF) extends Dickey Fuller by including extra lagged in terms of the dependent variables in order to eliminate the problem of autocorrelation (Mushtaq, 2011; Dickey and Fuller, 1979).

Having passed the ADF test, cointegration tests are performed on all possible combinations of pairs. To test for cointegration we adopted Engle and Granger 2-step approach and Johansen test. This methodology is based on J. Caldeira and G. V. Moura (Caldeira and Moura, 2013).

Engle and Granger (1987) present the representation theorem stating that if two or more series in $y_{t}$ are co-integrated, there is an error correction representation that takes the following form:

$$
\Delta y_{t}=\mu+\gamma z_{t-1}+\varepsilon_{t}
$$

Where $\gamma$ is a matrix of coefficient of dimension $n x r$ of rank $r, \mu$ is a (nx1) vector of constants, $z_{t-1}$ is of dimension $r x 1$ based on $r \leq n-1$ equilibrium error relationships, $z_{t}=\alpha^{\prime}$, the vector $y_{t}$ is said to be co-integrated if there is the $n x r$ matrix $\alpha$ is so that $z_{t}=\alpha^{\prime}$ and $y_{t}$ with $\varepsilon_{t}$ is a stationary multivariate disturbance (LeSage, 1999).

Johansen test determines the number of cointegrating relations and implements a multivariate extension of the 2-step Engle and Granger procedure (Caldeira and Moura, 2013).

All of the procedures are implemented on MATLAB. The second part of the algorithm creates trading signals for the detected cointegrating relations based on the predefined investment decision rules.

\section{Pairs trading strategies}

Right after the correlated pairs are identified for a given trading window, the pairs trading strategy searches for trading signals, and the latter differ depending on trading strategies. As it has already been mentioned, our research is based on three pairs trading strategies. Although they use the same methodology, their trading signal detection methods differ. The first strategy used was presented by J. Caldeira and G. V. Moura in their paper (Caldeira and Moura, 2013). Here, the detection of trading signals requires calculation of the difference $\varepsilon_{t}$ between the pair of normalized futures contracts prices:

$$
\varepsilon_{t}=P(i, t)-p(i, t)
$$

Where $\varepsilon_{t}$ is the difference between futures contract $P(i, t)$ and its pair $p(i, t)$ at time $t$. Next, upon calculating the difference, it is time to fine the threshold $z_{t}$ :

$$
z_{t}=\frac{\varepsilon_{t}-\mu_{t}}{\sigma_{t}}
$$

Where $\mu_{\varepsilon}$ is mean and $\sigma_{\varepsilon}$ is standard deviation of the found pair of the futures contracts for previous trading window. When $z_{t}$ value is calculated, the strategy may start searching for trading opportunities, which are based on the following rules (Caldeira and Moura, 2013):

Open long position, if $z_{t}<-2 \sigma$;

Open short position, if $z_{t}>2 \sigma$; 
Close short position, if $z_{t}<0.75 \sigma$

Close long position, if $z_{t}>-0.50 \sigma$ (Caldeira and Moura, 2013).

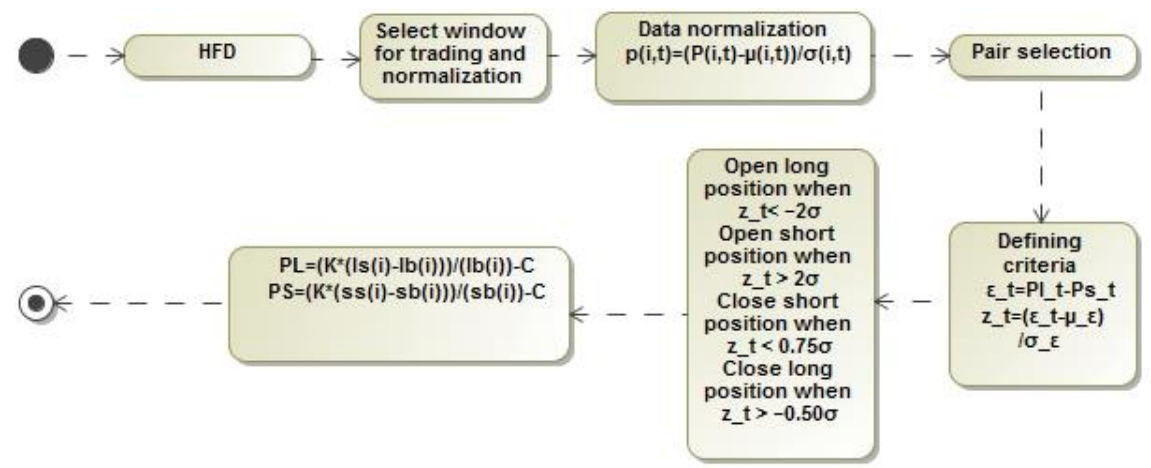

Fig. 2. J. Caldeira and G. V. Moura's pairs trading strategy

To clarify, it should be noted that every position is kept opened until the rule for closing is reached or the time to keep the positions opened goes out. Moreover, the attention should be paid to the fact that iterating confidence intervals (Bollinger bands) were used for these trading rules (Caldeira and Moura, 2013). Therefore, any reference to the mean or to the standard deviation is a reference to the specific in an iterating window process of 20 seconds. Due to the fact that our research is done to test the importance of high frequency data and to check if the higher frequency data brings better results, no commissions were taken into account. This was done due to fat that only the effectiveness of data each strategy was measured, not taking in to account how it would perform in real market. The second strategy is based on the research by M. S. Perlini, who developed his strategy for daily data (Perlin, 2009). Like in the case of J. Caldeira and G. V. Moura, here we must calculate the difference $\varepsilon_{t}$ between two normalized prices of futures contracts and measure it against the threshold $d$, which is defined by the trader. Upon calculating the difference, long and short positions are established. For example, if we have two commodity futures contracts $A$ and $B$, one pair for the selected trading window would be $A(i, t)$ and $B(i, t)$, if the normalized price of $A(i, t)$ is higher than $B(i, t)$, then a short position is taken on $A(i, t)$ and long on $B(i, t)$, in other case, short position on $B(i, t)$ and long on $A(i, t)$ (Perlin, 2009).

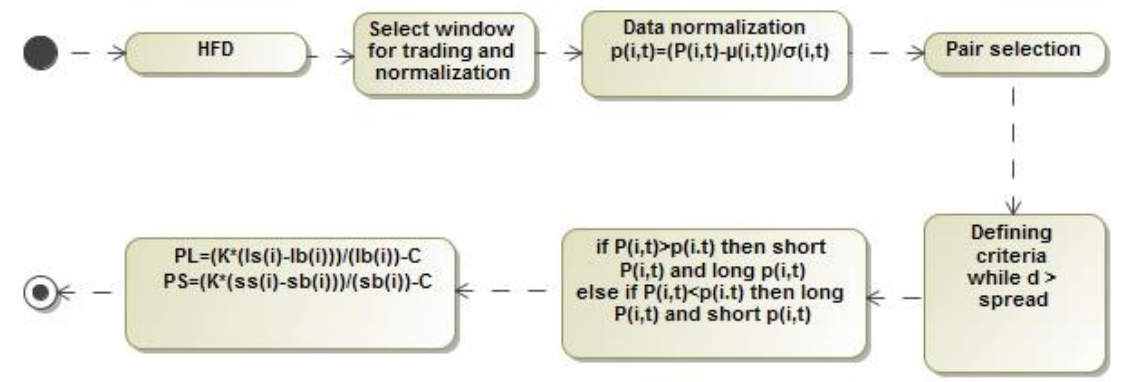

Fig. 3. M. S. Perlini's pairs trading strategy 
Importantly, these positions are kept opened till the spread becomes smaller than the threshold $d$. The detailed trading rules are presented below:

while $d>$ spread;

if $A(i, t)>B(i . t)$, then short $A(i, t)$ and long $B(i, t)$;

in other case, long $A(i, t)$ and short $B(i, t)$ (Perlin, 2009).

The basic idea of M. S. Perlini pairs trading strategy is to follow the distance between the pair of correlated futures contracts normalized prices and wait till the threshold $d$ is reached as then there is a probability that the prices are going to converge in the future and this opportunity can be exploited to gain the profit (Perlin, 2009).

Final pairs trading strategy was based on D. Herlemont research, where he presented his strategy for daily trading. In his paper the author researched theoretical pairs trading model, focused on its efficiency and was looking to find the right method for pair selection and correlation. For our research we only used the pairs trading model, which he presented in his research (Herlemont, 2013).

For this trading strategy we must first calculate the mean $\mu_{t}$ and standard deviation $\sigma_{t}$ for given trading window of the differences of normalized futures contract prices. Once we have both criteria calculated the strategy may look for trading signals. When the difference of prices of found futures contract pair $A$ and $B$ price is $<2 * \sigma_{t}$ :

If $A_{t}>B_{t}$, then open short position with $A_{t}$ and long position with $B_{t}$;

If $A_{t}<B_{t}$, then open long position with $A_{t}$ and short position with $B t$ (Herlemont, 2013).

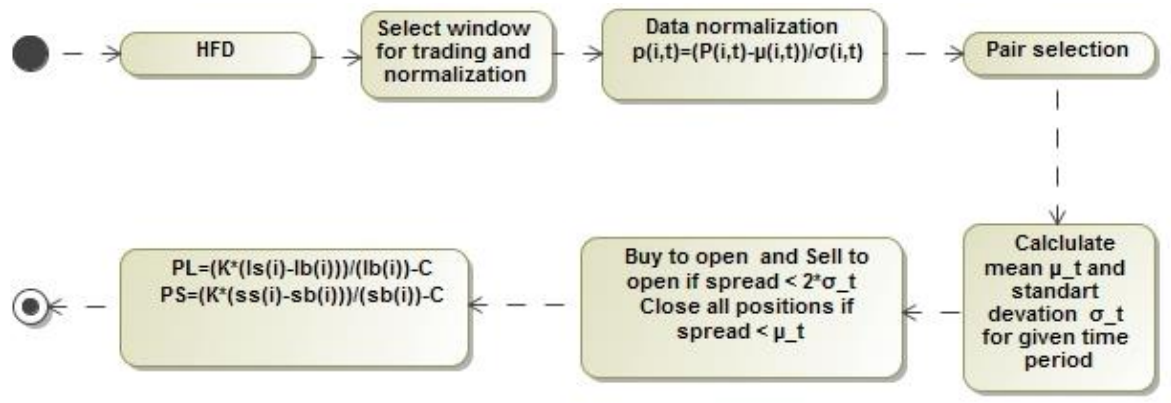

Fig. 4. D. Herlemon's pairs trading strategy

All positions should be closed when the differences between normalized prices of $A_{t}$ and $B_{t}$ are $<\mu_{t}$, or the maximum period to keep the positions opened is reached (Herlemont, 2013).

All criteria and methods are kept the same for both data groups of microseconds and nanoseconds, since this research is based on measuring the effectiveness of different frequency data and its effect on the pairs trading using high performance computing.

Finally, it is important to measure the performance of each pairs trading strategy with high frequency data of microseconds and nanoseconds. The performance was determined by the profit that each high frequency pairs trading strategy generated. The profit came from trading the correlated futures commodity contracts for a given period based on the strategies trading rules. Hence, at the end of the research all arrays for each pairs trading strategy with real prices for opening and closing long or short positions were employed to measure the result of the pairs trading strategy. For more details see 
the equations below that explain the calculations for the profit/loss (Perlin, 2009; Vaitonis and Masteika, 2016):

$$
\begin{aligned}
& P L=\sum_{i=1}^{K}(l s(i)-l b(i), \\
& P S=\sum_{i=1}^{K}(s s(i)-s b(i) .
\end{aligned}
$$

The variable $P L$ represents the profit from a long position and the variable $P S$ - the profit from a short position, while the variable $i$ represents the trade, which the profit/loss is calculated for. The profit from a long position is the difference between futures commodity contract $i$ sell $-l s$ and buy $-l b$ values that are multiplied by $K$, representing the number of contracts. The profit/loss for short positions is found in similar manner, where it is equal to the difference between futures commodity contract $i$ sell $-s s$ and buy $-s b$, multiplied by $K$. Finally, at the end of each algorithm, the total profit was calculated (Perlin, 2009; Vaitonis and Masteika, 2016):

$$
T P=P L+P S
$$

Once all calculations were done, performances in percentages were presented.

\section{Performance}

All three high frequency pairs trading strategies were based on the market-neutral strategy. These strategies opened long and short positions simultaneously when the specified trading criteria were met. All buy and short orders were made on the market prices, which means that the buy signal was created with ask price and short with sell price.

Before analyzing the results of this research, it is worth to mention that the total return is considered to be the sum of long and short positions for each pairs trading strategy separately. This is achieved if a pair of futures contracts is detected and long and short positions are taken. Furthermore, these contracts cannot consist of a pair of other contracts for the given pairs trading strategy. In order to illustrate, it might be stated that at the time $t$, one futures contract can have only long or short positions taken, based on the trading rules of the pairs trading strategy. For the sake of this research, the transaction cost was kept at 0 as many markets provide low or even no transaction costs due to the fact that high frequency traders bring liquidity to the market.

Importantly, all three high frequency pairs trading strategies generated positive results using both data sets of microseconds and nanoseconds.

The figure below summarizes the results of all three pairs trading strategies with nanosecond data for our trading period from 2015-08-01 to 2015-08-31. As it might be seen, it reveals the summed up profit that these strategies generated each day (Fig. 5). 


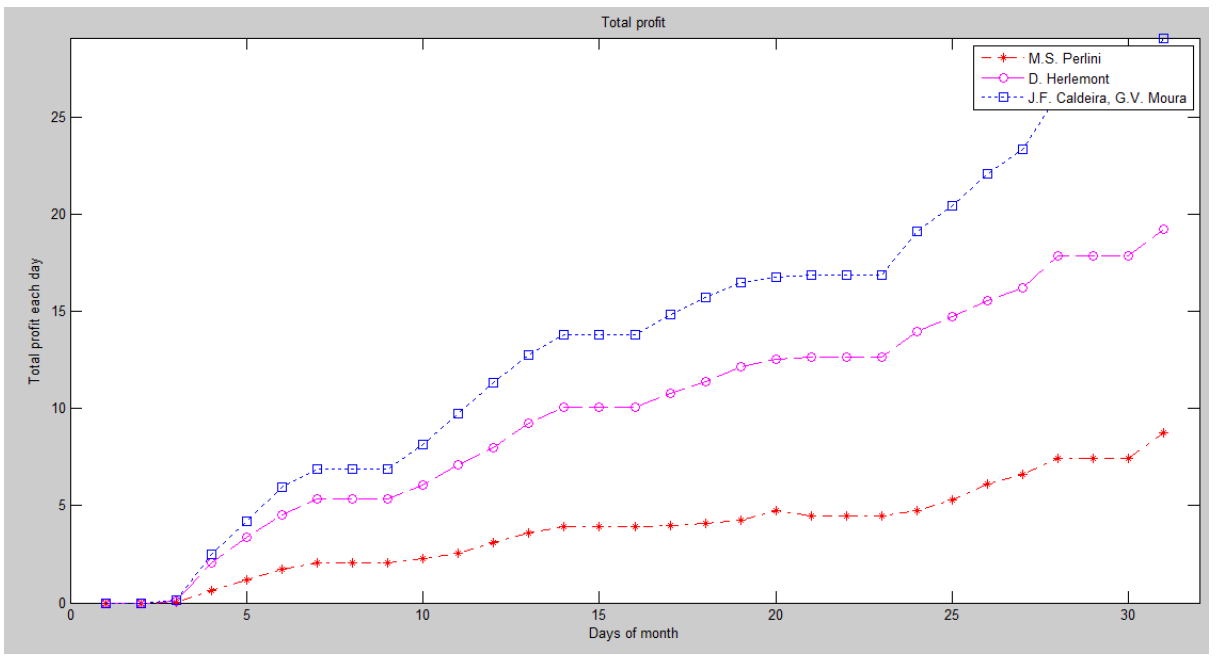

Fig. 5. Summed up daily profit of each pairs trading strategy with nanosecond historical data

It is interesting to see how many trades each high frequency pairs trading strategy made for each day when using nanosecond data (Fig. 5).

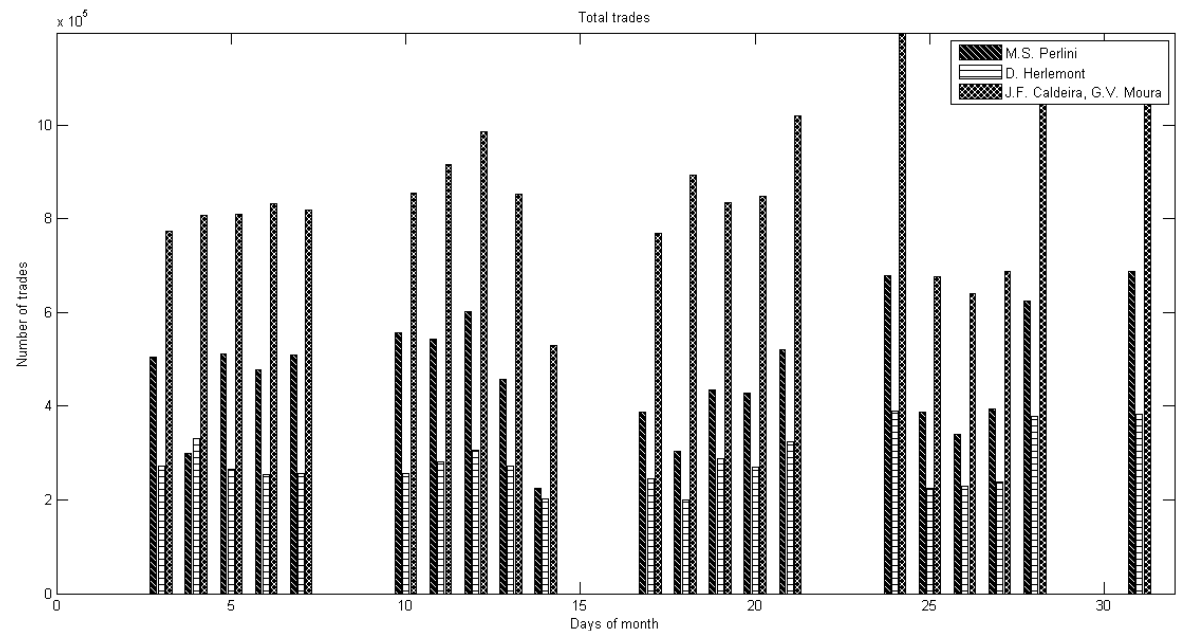

Fig. 6. Number of daily trades of each pairs trading strategy with nanosecond data

The number of trades depends on the trading rules of each strategy: the more sensitive the strategy is, the more trading signals are generated. Although high number of trades not always results in good performance, in our case higher number of trades was characterized by better performance. 
Table 3. Research results for microsecond and nanosecond data

\begin{tabular}{|l|c|c|c|}
\hline & M. S. Perlini & D. Herlemont & $\begin{array}{c}\text { J. Caldeira and } \\
\text { G. V. Moura }\end{array}$ \\
\hline $\begin{array}{l}\text { Profit with } \\
\text { nanosecond data }\end{array}$ & $8.74 \%$ & $19.27 \%$ & $29.11 \%$ \\
\hline $\begin{array}{l}\text { The number of } \\
\text { total trades }\end{array}$ & 9878627 & 5869860 & 18051372 \\
\hline $\begin{array}{l}\text { Profit with } \\
\text { microsecond data }\end{array}$ & $4.01 \%$ & $3.39 \%$ & $4.75 \%$ \\
\hline $\begin{array}{l}\text { Number of the total } \\
\text { trades }\end{array}$ & 1491576 & 2135360 & 2538979 \\
\hline
\end{tabular}

In the table above the total profits and trades of M. S. Perlini, D. Herlemont and J. Calderia with G. V. Moura's pairs trading strategies are shown. M. S. Perlini's strategy generated $8.74 \%$ profit with 9878627 trades. D. Herlemont pairs trading strategy generated the lowest number of trades, i.e., 5869860 with $19.27 \%$ of the total profit. The last high frequency trading strategy presented by J. Caldeira and G. V. Moura generated the highest number of trades - 18051372 that resulted in high profit at the end of the month, i.e., $29.11 \%$. Considering these results, it might be concluded that J. Caldeira and G. V. Moura's trading strategy is characterized by the best performance as it generated the highest number of trades. From the results shown in the table we can calculate the average return for each pairs trading rule with microsecond and nanosecond data.

Table 4. The average return per trade for each data set and pairs trading strategy.

\begin{tabular}{|l|l|r|r|}
\hline & M. S. Perlini & D. Herlemont & $\begin{array}{r}\text { J. Caldeira and } \\
\text { G. V. Moura }\end{array}$ \\
\hline $\begin{array}{l}\text { The average return } \\
\text { with microsecond } \\
\text { data }\end{array}$ & $0.00000088 \%$ & $0.00000328 \%$ & $0.00000161 \%$ \\
\hline $\begin{array}{l}\text { The average return } \\
\text { with nanosecond } \\
\text { data }\end{array}$ & $0.00000269 \%$ & $0.00000159 \%$ & $0.00000187 \%$ \\
\hline
\end{tabular}

However, the average return does not always indicate the most effective pairs trading strategy. Thus, in order to find one, the Sharpe Ratio was calculated for each strategy. 
Table 5. Profit in percentage for each trading day

\begin{tabular}{|l|l|l|r|r|r|r|}
\hline Date & $\begin{array}{l}\text { M. S. } \\
\text { Perlini in } \\
\text { ns. }\end{array}$ & $\begin{array}{l}\text { M. S. } \\
\text { Perlini } \\
\text { in ms. }\end{array}$ & $\begin{array}{l}\text { D. } \\
\text { in ns. }\end{array}$ & $\begin{array}{l}\text { D. } \\
\text { in ms. }\end{array}$ & $\begin{array}{l}\text { J. Caldeira } \\
\text { and G. V. } \\
\text { Moura in } \\
\text { ns. }\end{array}$ & $\begin{array}{l}\text { J. Caldeira } \\
\text { and G. V. } \\
\text { Moura in } \\
\text { ms. }\end{array}$ \\
\hline $2015-08-3$ & 0.2991 & 0.2861 & 0.9131 & 0.1344 & 1.2460 & 0.0482 \\
\hline $2015-08-4$ & 0.3290 & 0.0951 & 1.1628 & 0.2393 & 1.2570 & 0.0274 \\
\hline $2015-08-5$ & 0.5558 & 0.2684 & 1.3029 & 0.3997 & 1.6732 & 0.0153 \\
\hline $2015-08-6$ & 0.5296 & 0.2605 & 1.1581 & 0.3367 & 1.8100 & 0.2466 \\
\hline $2015-08-7$ & 0.3334 & 0.1725 & 0.8016 & 0.2540 & 0.9110 & 0.1888 \\
\hline $2015-08-10$ & 0.2338 & 0.2397 & 0.7086 & 0.2693 & 1.2510 & 0.1669 \\
\hline $2015-08-11$ & 0.2551 & 0.2910 & 1.0476 & 0.3316 & 1.6160 & 0.2252 \\
\hline $2015-08-12$ & 0.5766 & 0.3343 & 0.8812 & 0.1070 & 1.5960 & 0.3285 \\
\hline $2015-08-13$ & 0.4855 & 0.2346 & 1.2720 & 0.1013 & 1.4030 & 0.3322 \\
\hline $2015-08-14$ & 0.3569 & 0.1116 & 0.8347 & 0.0929 & 1.0600 & 0.2173 \\
\hline $2015-08-17$ & 0.0275 & 0.0753 & 0.7157 & 0.0425 & 1.0260 & 0.1978 \\
\hline $2015-08-18$ & 0.1219 & 0.0597 & 0.6141 & 0.0370 & 0.8660 & 0.1121 \\
\hline $2015-08-19$ & 0.1439 & 0.1856 & 0.7636 & 0.0425 & 0.8120 & 0.2317 \\
\hline $2015-08-20$ & 0.4791 & 0.1352 & 0.3591 & 0.0443 & 0.2390 & 0.1909 \\
\hline $2015-08-21$ & -0.2500 & 0.0917 & 0.1180 & 0.0754 & 0.1100 & 0.1201 \\
\hline $2015-08-24$ & 0.2562 & 0.2031 & 1.3034 & 0.1552 & 2.2730 & 0.2941 \\
\hline $2015-08-25$ & 0.5519 & 0.0860 & 0.7722 & 0.0504 & 1.3350 & 0.1795 \\
\hline $2015-08-26$ & 0.8523 & 0.1502 & 0.8247 & 0.0539 & 1.6130 & 0.2987 \\
\hline $2015-08-27$ & 0.5036 & 0.1992 & 0.6949 & 0.1271 & 1.2850 & 0.3636 \\
\hline $2015-08-28$ & 0.7844 & 0.2974 & 1.6071 & 0.3190 & 2.7860 & 0.5674 \\
\hline $2015-08-31$ & 1.3203 & 0.2296 & 1.4236 & 0.1759 & 2.9440 & 0.3922 \\
\hline
\end{tabular}

Before calculating the Sharpe Ratio for each pairs trading strategy, we have to look at how each strategy performs every day with different data. The table above shows the daily profit in percentage for M. S. Perlini, D. Herlemont and J. Caldeira with G. V. Moura's trading strategies using microsecond and nanosecond data. As it can be seen, all strategies with both types of data performed positive. The figure below shows the total profits from a different perspective. The first group represents the pairs trading with nanoseconds, while the second group - with microseconds (Fig. 7).

The figure shows an obvious difference in profitability. However, we must measure this profit against the conducted trades and calculate the Sharpe Ratio for each of the three pairs trading strategies with microsecond and nanosecond data.

The next step of this research is to analyze the trades made for each strategy (Fig. 8). It should be no surprise that the use of nanosecond data resulted in higher number of trades for all pairs trading strategies by M. S. Perlini, D. Herlemont and J. Caldeira with G. V. Moura. 


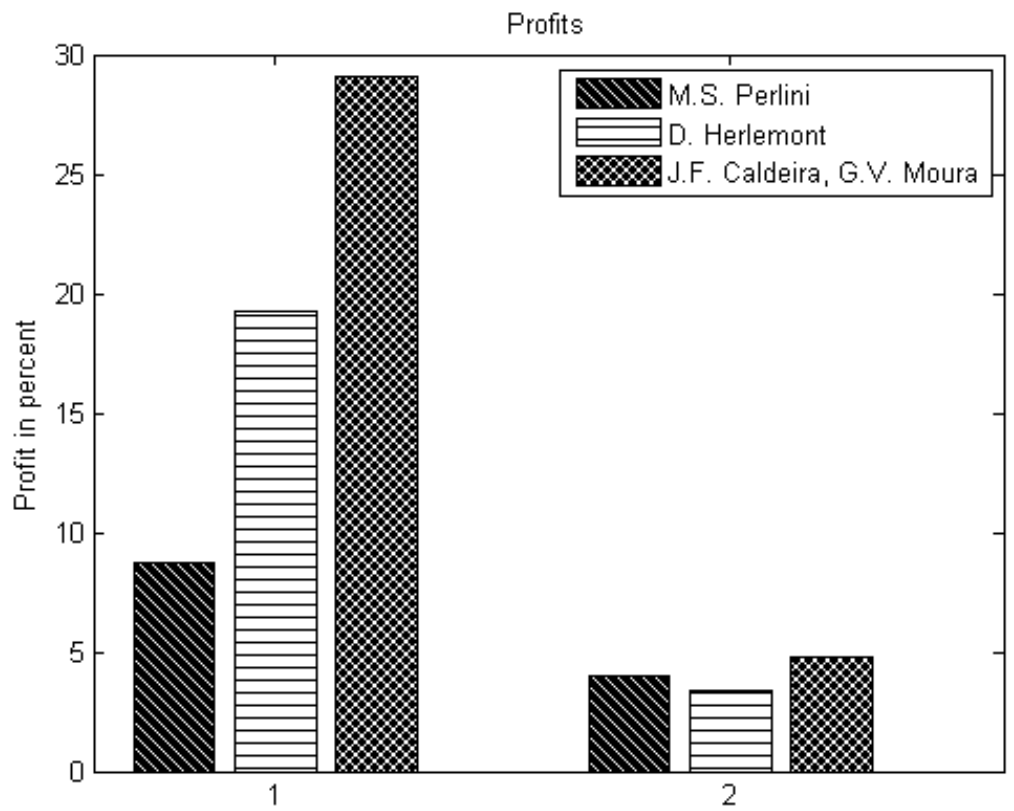

Fig. 7. The total profit in percentage of each pairs trading strategy using both microsecond and nanosecond data

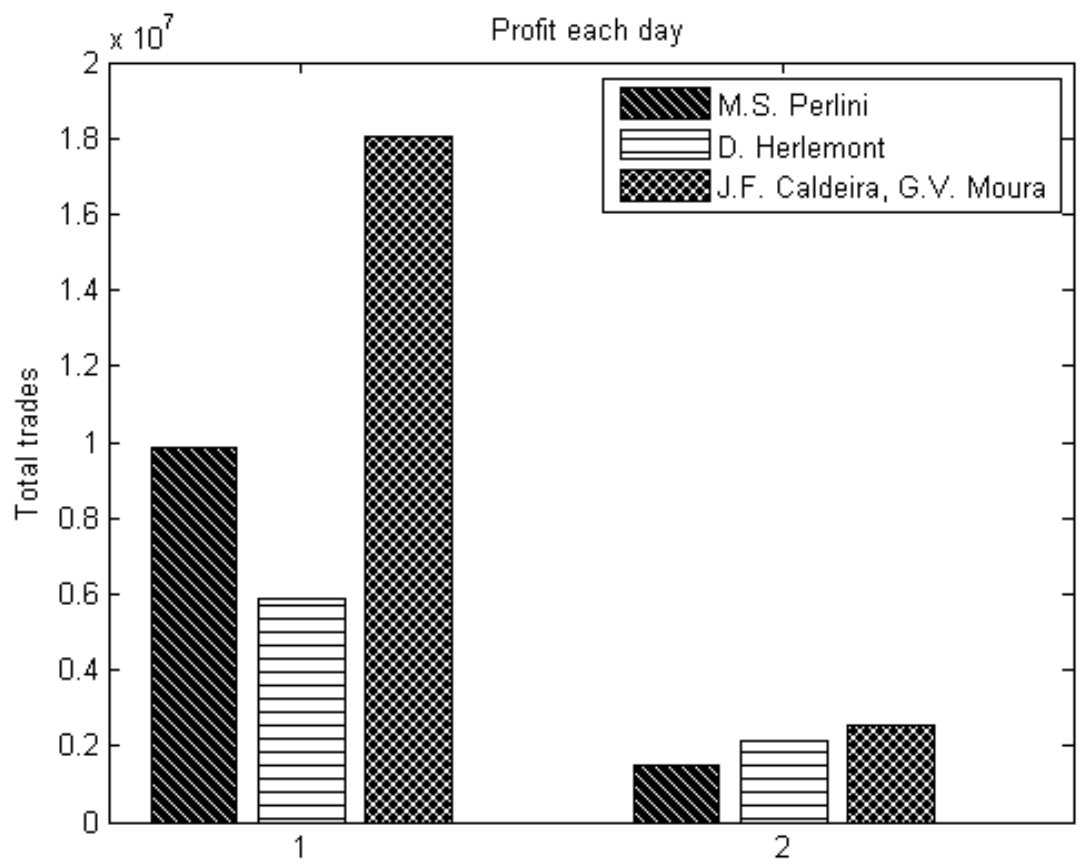

Fig. 8. The total number of trades of each pairs trading strategy using both microsecond and nanosecond data 
Upon obtaining all information about the pairs trading strategies for microsecond and nanosecond historic data, the Sharpe Ratio is calculated.

The Sharpe Ratio is calculated by using the formula $S=\frac{\mu_{P n L}}{\sigma_{P n L}}$, where $\mu_{P n L}$ is the mean of profit and loss and $\sigma_{P n L}$ is the standard deviation for $P n L$. In this way, the Sharpe Ratio was calculated for each strategy with nanosecond and microsecond data.

Table 6. The Sharpe Ratio of each pairs trading strategy with microsecond and nanosecond historical data

\begin{tabular}{|l|c|c|c|}
\hline & $\begin{array}{c}\text { Sharpe ratio of } \\
\text { M. S. Perlini } \\
\text { strategy }\end{array}$ & $\begin{array}{c}\text { Sharpe ratio of } \\
\text { D. Herlemont } \\
\text { strategy }\end{array}$ & $\begin{array}{c}\text { Sharpe ratio of } \\
\text { J. Caldeira and } \\
\text { G. V. Moura } \\
\text { strategy }\end{array}$ \\
\hline Microsecond data & 1.3380 & 1.4240 & 1.7651 \\
\hline Nanosecond data & 1.3144 & 2.6388 & 2.0442 \\
\hline
\end{tabular}

In general, the higher the Sharpe Ratio is, the better strategy it represents. The table above reveals that J. Caldeira and G. V. Moura's high frequency pairs trading strategy was characterized by the best performance with microsecond data. However, upon introducing nanosecond historical data, it was outperformed by the pairs trading strategy of D. Herlemont. It might seem obvious due to the fact that J. Caldeira and G. V. Moura's strategy resulted in significantly higher number of trade signals in comparison D. Herlemont's one, it is known that high number of trades not always indicates better performance. It means that a lot of trade signals are unnecessary and may be filtered. The table also shows that the best performance was reached using nanosecond data. Two out of three strategies resulted in better performance when presented to higher frequency data. High frequency data allows the trader to work with the newest information in the fastest way. Moreover, with this type of data it is possible to set narrow time windows around each trading strategy, thus, making it easier to react to all abnormalities in the market. It should be noted that the main advantage of high frequency data is the fact that the trader can overcome other traders as he receives information faster, in turn, he can make decisions faster. As this experiment shows, the information with the highest frequency makes the pairs trading strategy more effective.

As mentioned before no commissions were used for each trade. It might be crucial when presenting these strategies to the real electronic markets. For example the size of commission may be $\$ 0.003$ for HFT market makers (US SEC, 2015). In our research the most profitable strategy was by J. Caldeira and G. V. Moura with nanosecond data, on day 2015-08-31 that ended in 2,9440 \% of profit when no commission were used. If the commission of $\$ 0.003$ would have been used, the profit would change to the loss of $154,1900 \%$. Due to the high number of trades, when commissions are applied the overall profitability change and bring loss to the trader. However, many electronic markets ask for low or sometimes even no commissions from high frequency traders, due to the fact that HFT traders bring liquidity to the market. Thus, before applying trading strategy the trader should check the size of commission in the market he plans to trade on. 


\section{Conclusions}

This research is based on different pairs trading strategies presented by four different authors. The first pairs trading strategy was brought by M. S. Perlini, the second - by D. Herlemont, and the third by J. Caldeira and G. V. Moura. Previously all of these strategies were based only on low frequency data and trading. Therefore, this research modified them to work with high frequency data of microseconds and nanoseconds. Moreover, they had to be implemented on MATLAB platform.

In this paper, high frequency algorithmic pairs trading was developed on the market-neutral statistical arbitrage strategies. Importantly, all five futures commodity contracts used for the proposed pairs trading strategies belong to same CME group, which is the world's largest options and futures exchange platform. All three proposed trading strategies used the same pairs selection algorithm which consisted of the Augmented Dickey Fuller. If the prices of futures commodity contracts pass the Augmented Dickey Fuller test, cointegration tests are performed to all possible combinations of pairs. To test for cointegration we adopted Engle and Grangers 2-step approach and Johansen test.

All trading parameters were kept the same for all three pairs trading strategies for both datasets of microseconds and nanoseconds. The purpose of this was to measure the effectiveness of data and to check whether higher frequency data improve the performance of the pairs trading strategies.

At the end of the research, when all datasets were implemented to the pairs selection algorithm and three pairs trading strategies, the results were gathered. It should be no surprise that nanosecond data proved to be more effective that microsecond. In conclusion, it might be stated that higher frequency data provide the trader with newest information, allow to react faster and notice every change in the market. The results are presented in the table below:

Table 7. Research results for microsecond and nanosecond data

\begin{tabular}{|l|c|c|c|}
\hline & M. S. Perlini & D. Herlemont & $\begin{array}{c}\text { J. Caldeira } \\
\text { and G. V. Moura }\end{array}$ \\
\hline $\begin{array}{l}\text { The profit with } \\
\text { nanosecond data }\end{array}$ & $8.74 \%$ & $19.27 \%$ & $29.11 \%$ \\
\hline $\begin{array}{l}\text { The number of } \\
\text { total trades }\end{array}$ & 9878627 & 5869860 & 18051372 \\
\hline $\begin{array}{l}\text { The profit with } \\
\text { microsecond data }\end{array}$ & $4.01 \%$ & $3.39 \%$ & $4.75 \%$ \\
\hline $\begin{array}{l}\text { The number of } \\
\text { total trades }\end{array}$ & 1491576 & 2135360 & 2538979 \\
\hline
\end{tabular}

In the next step, the Sharpe Ratio was applied to prove that nanosecond data were more effective. It was calculated for each of three pairs trading strategies and for both datasets. When using microsecond data, the Sharpe Ratio of M. S. Perlini was 1.3144, D. Herlemont -1.4240 and J. Caldeira with G. V. Moura - 1.7651. Meanwhile, in the case of nanosecond data the Sharpe Ratio of M. S. Perlini was 1.3144, D. Herlemont -2.6388 and J. Caldeira with G. V. Moura - 2.0442. It should be emphasised that the highest 
Sharpe Ratio was reached by D. Herlemont strategy with nanosecond data. Thus, the latter strategy may be used for the futures developments, while the other two may be selected to detect what caused them to be less effective and to attempt to improve them. More importantly nanosecond data proved to be more effective than microsecond data. Thus, nanosecond data can be used for further development of high frequency trading.

Nevertheless, the most effective pairs trading strategy of D. Herlemont might need additional analysis in real time high frequency trading environment before applying it in real market. This involves the evaluation of trading infrastructure costs, bidirectional arbitrage, and making sure that the market provides no transaction costs due to liquidity. Otherwise the results may differ due to the high number of trades. It is possible to increase the performance of this strategy, however, further developments are needed which may involve research on the same strategy with different sectors of futures contracts, for example, metals, grains, currencies. In general, the pairs trading strategies give positive results with both microsecond and nanosecond data, yet the best results are reached when using nanosecond historical data. These results might be important not only to the market participants, market infrastructure and trading algorithm developers, but also to artificial intelligence developers, who consider that fast decision making is of utmost important.

\section{Acknowledgements}

We would like to show our gratitude to the NANOTICK for providing high frequency data in nanoseconds and microseconds of 5 commodity futures contracts.

\section{References}

Ahmed M., Chai A., Ding X., Jiang Y., Sun Y. (2009). Statistical Arbitrage in High Frequency Trading Based on Limit Order Book Dynamics. Available at https://web.stanford.edu/class/msande444/2009/2009Projects/2009-2/MSE444.pdf.

Ahmet G. (2015). Statistical arbitrage in the Black-Scholes framework. Quantitative Finance, Vol. 15(9), pp. 1489-1499.

Aldrige I. (2013). High-Frequency Trading: A Practical Guide to Algorithmic Strategies and Trading Systems. Wiley; 2 edition, p.306.

Antoin B., Cyrille G., Carlos A. R., Christian W., Steffen N. (2014), High-frequency trading activity in EU equity markets, Economic Report. Volume 1.

Bogoev D., Karam A. (2016). An Empirical detection of High Frequency Trading Strategies, 6th International Conference of the Financial Engineering and Banking Society. June 10-12, 2016 Melaga.

Botos B., Nagy L., Ormos M. (2014). Pairs Trading Arbitrage Strategy in the Old and New EU Member States, ICFB.

Brogaard J., Hendershott J. T., Riordan R. (2013). High frequency trading and price discovery, ECB Lamfalussy fellowship programme/ Working paper series, No 1602, European central bank Press.

Burton G. M. (2003). The Efficient Market Hypothesis and Its Critics, Journal of Economic Perspectives, Vol. 17(1), pp. 59 - 82.

Caldeira J., Moura G. V. (2013). Selection of a portfolio of pairs based on cointegration: A statistical arbitrage strategy, Revista Brasileira de Financas, Vol. 11(1), pp. 49-80.

Carrion A. (2013). Very fast money: High - frequency trading on the NASDAQ, Journal of Financial Markets, Vol. 16(4), pp. 680 - 711. 
Cifu D. A. (2014). FORM S-1, Registration Statement Under The Securities Act Of 1933, Virtu Financial, Inc.

Cvitanic J., Kirilenko A. (2010). High Frequency Traders and Asset Prices. Available at SSRN: http://ssrn.com/abstract=1569067 or http://dx.doi.org/10.2139/ssrn.1569067.

Dickey D., Fuller W. (1979). Distribution of the Estimator for Autoregressive Time series with a Unit Root, Journal of the American Statistical Association, Vol. 74, pp. 427-431.

Drakos S. (2016). Statistical Arbitrage in S\&P500, Journal of Mathematical Finance, Vol. 6, pp. 166-177.

Driaunys K., Masteika S., Sakalauksas V., Vaitonis M. (2014). An algorithm-based statistical arbitrage high frequency trading system to forecast prices of natural gas futures, Transformations in business and economics. Vol. 13(3), p. 96-109.

Eichengreen J. B. (1998). Hedge Funds and Financial Market Dynamics, Intl. Monetary Fund, p.83.

Engle, R. F., Granger, C. W. J. (1987). Co-integration and error correction: Representation, estimation, and testing, Econometrica, Vol. 55(2), pp. 251-276.

Fox M. B., Glosten L. R., Rauterberg G. V. (2015). The New Stock Market: Sense and Nonsense, 65 Duke L.J. 191.

Goldstein M. A., Pavitra K., Frank C. G. (2014). Computerized and High-Frequency Trading, Financial Review, Vol. 49(2), pp. 177-202.

Hagströmer B., Norden L. (2013). The diversity of high-frequency traders, Journal of Financial Markets, Vol. 16(4), pp. 741-770.

Herlemont D. (2013). Pairs Trading, Convergence Trading, Cointegration, Quantitative Finance, Vol. 12(9).

Jaramillo C. (2016). The Revolt against High-Frequency Trading: From Flash Boys, to Class Actions, to IEX, Review of banking \& financial law, Vol. 35, pp. $483-499$.

Kaya O. (2016). High - frequency trading. Reaching the limits, Automated trader magazine. Vol. 41, p. $23-27$.

Kirchner S. (2015). High frequency trading: Fact and fiction, Policy: A Journal of Public Policy and Ideas, Vol. 31(4), pp. 8-20.

Krauss C. (2015). Statistical arbitrage pairs trading strategies: Review and outlook, IWQW Discussion Paper Series, No. 09/2015.

Lau C. A., Xie W., Wu Y. (2016). Multi - Dimensional Pairs Trading Using Copulas, European Financial Management Association 2016 Annual Meetings June 29-July 2, 2016 Basel, Switzerland.

LeSage J. P. (1999). The theory and practice of spatial econometrics. Available at http://www.spatial-econometrics.com/html/sbook.pdf.

Madhavaram G. R. (2013). Statistical Arbitrage Using Pairs Trading With Support Vector Machine Learning, Saint Mary's University. Available at http://m.library2.smu.ca/bitstream/handle/01/25225/madhavaram_gopal_r_mrp_2013.pdf?sequ ence $=1 \&$ isAllowed $=\mathrm{y}$.

Masteika S., Vaitonis M. (2015). Quantitative Research in High Frequency Trading for Natural Gas Futures Market, Business Information Systems Workshops, Vol. 228, pp. 29-35.

Miao G. J. (2014). High Frequency and Dynamic Pairs Trading Based on Statistical Arbitrage Using a Two-Stage Correlation and Cointegration Approach, International Journal of Economics and Finance, Vol. 6(3), pp. $96-110$.

Miao G. J., Clements M. A. (2002). Digital Signal Processing and Statistical Classification, Artech House, London, ISBN 1580531350.

Miao J. G. (2014). High Frequency and Dynamic Pairs Trading Based on Statistical Arbitrage Using a Two-Stage Correlation and Cointegration Approach, International Journal of Economics and Finance, Vol.6 (3), pp. 96-110.

Miller R. S., Shorter G. (2016). High Frequency Trading: Overview of Recent Developments, report, April 4, 2016; Washington D.C. 
Miller S. J. (2006). The method of least squares, Mathematics Department Brown University. Available at https://web.williams.edu/Mathematics/sjmiller/public_html/BrownClasses/54/ handouts/MethodLeastSquares.pdf

Mushtaq R. (2011). Augmented Dickey Fuller Test. Available at SSRN: https://ssrn.com/abstract=1911068.

Ohara M. (2015). High frequency market microstructure, Journal of Financial Economics, Vol. 116(2), pp. 257-270.

Perlin M. S. (2009). Evaluation of Pairs-trading strategy at the Brazilian financial market, Journal of Derivatives \& Hedge Funds, Vol. 15(2), pp. 122-136.

U.S. Securities and Exchange Commission (2015). Maker-Taker Fees on Equities Exchanges Memorandum from Division of Trading and Markets to the SEC Market Structure Advisory Committee. Available at: https://www.sec.gov/spotlight/emsac/memo-maker-taker-fees-onequities-exchanges.pdf

Vaitonis M. (2017). Pairs Trading Using HFT in OMX Baltic Market, Baltic J. Modern Computing, Vol. 5(1), pp. 37-49.

Vaitonis M., Masteika S. (2016). Research in High Frequency Trading and Pairs Selection Algorithm with Baltic Region Stocks, In: Dregvaite G., Damasevicius R. Information and Software Technologies. ICIST 2016. Communications in Computer and Information Science, Vol 639. Springer.

Vaitonis M., Masteika S. (2017). Statistical arbitrage trading strategy applied on future commodity market using nanosecond information, ICIST 2017, Communications in Computer and Information Science, Vol 756. Springer.

Vidyamurthy G. (2004). Pairs Trading - Quantitative Methods and Analysis, New Jersey, John Wiley \& Sons, Inc., p. 210.

Zubulake P., Lee S. (2011). The High frequency game changer: how automated trading strategies have revolutionized the markets, Aite group. Wiley trading, pp. 47-87.

Received December 3, 2017, accepted June 15, 2018 